\title{
Effect of Temperature on the Ion Beam Induced Luminescence of Oxide Powders Doped with Rare Earth Elements
}

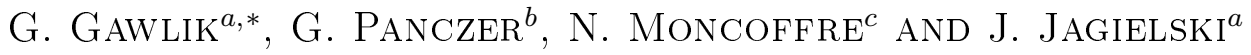 \\ ${ }^{a}$ Institute of Electronic Materials Technology (ITME), Wólczyńska 133, 01-919 Warszawa, Poland \\ ${ }^{b}$ Laboratoire de Physico-Chimie des Matériaux Luminescents UMR 5620 CNRS, Lyon 1 University, Lyon, France \\ ${ }^{c}$ Institut de Physique Nucléaire, Lyon, France
}

\begin{abstract}
The hydrogen ion beam induced luminescence of gadolinium oxide $\mathrm{Gd}_{2} \mathrm{O}_{3}$ doped with $1 \%$ of holmium (Ho) and $1 \%$ of bismuth (Bi) was investigated. Degradation of the holmium related $549 \mathrm{~nm}$ ion beam induced luminescence line intensity during hydrogen ion irradiation was observed. Two different mechanisms of the ion beam induced luminescence degradation has been proposed: the first one related to the accumulation of ion induced target material damage and the second mechanism related to the target temperature growth during ion beam bombardment. The experimental method for separation of both mechanisms effects was proposed and demonstrated.
\end{abstract}

DOI: 10.12693/APhysPolA.123.920

PACS: $78.60 . \mathrm{Hk}$

\section{Introduction}

Oxide materials are widely used in nuclear installations and in space vehicles where they are subjected to degradation by energetic particle irradiation. Ionoluminescence (IL) or ion beam induced luminescence (IBIL) is a material characterization method based on excitation of material luminescence by incident ions. This method is unique because of its ability to provide in situ information about recombination centers in the target material during ion beam bombardment.

Ionoluminescence as the characterization method has been investigated for last few years [1-17] and has been successfully used for characterization of scintillating materials [2], impurity detection [6, 17], in artwork characterization and mineral or artificial gems identification $[11,13]$ and for other materials characterization as well. However, the main disadvantage of this method is material degradation and modification of ionoluminescent spectra by ion beam bombardment during measurement. Ion beam energy dissipation in target leads to generation of structural defects and elevation of target material temperature. Both effects may affect luminescence of the material. It seems that fast recording of spectra changes during ion beam bombardment may provide information useful for resolving degradation and thermal effects.

The main idea of this work is based on the assumption that ion induced defects are accumulated during ion implantation and defect concentration is mainly fluence dependent. On the other hand, the net thermal effect should be recovered after cooling of the target material. The step by step implantation process has been developed with cooling stages without ion beam irradiation

*corresponding author; e-mail: grzegorz.gawlik@itme.edu.pl between ion implantation steps during which the temperature can increase.

\section{Experiment}

The molecular hydrogen $\left(\mathrm{H}_{2}^{+}\right)$ion beam of the energy $100 \mathrm{keV}$ has been used for excitation of ionoluminescence. The holmium (Ho) and bismuth (Bi) doped gadolinium oxide powder $\left(\mathrm{Gd}_{2} \mathrm{O}_{3}: 1 \% \mathrm{Ho}, 1 \% \mathrm{Bi}\right)$ was used as target material. Concentrations of both dopants ( $\mathrm{Ho}$ and $\mathrm{Bi}$ ) were $1 \%$. The gadolinium oxide powder was produced using the sol-gel method. The density of ion beam current was $J=9 \mu \mathrm{A} / \mathrm{cm}^{2}$ and it was stable during the whole measurement time. IBIL spectra in the wavelength range from $300 \mathrm{~nm}$ to $1000 \mathrm{~nm}$ were recorded using the Hamamatsu minispectrometer equipped with the CCD camera and fiber optic waveguide input. All experiments were performed in the vacuum chamber of the ion implantation system. The optical signal was collected and guided by the fiber optic waveguide through the optical vacuum feedthrough to the minispectrometer. Every single spectrum was recorded using the signal collection time $0.5 \mathrm{~s}$. The series of 100 spectra were recorded during the total time $50 \mathrm{~s}$ while each ion irradiation was run. Such fast measurement allows to detect time dependent IBIL changes with time resolution up to $0.5 \mathrm{~s}$. Taking into account that the temperature can influence the IBIL signal all measurements were made in series of $50 \mathrm{~s}$ ion beam irradiation runs divided by ion beam breaks each lasting one minute for cooling down the target material. Ion beam irradiation was applied about one second after starting of the IBIL measurement in each irradiation run. This technique ensures recording the first IBIL spectrum at the beginning of the ion beam irradiation of the cooled sample.

The gadolinium oxide $\left(\mathrm{Gd}_{2} \mathrm{O}_{3}\right)$ powder was placed onto a small tray at the angle 30 degrees to the ion beam direction. The fiber optic waveguide tip was directed to 
the ion beam footprint on the sample powder surface at the angle 90 degrees to the ion beam direction.

\section{Results and discussion}

Powder of $\mathrm{Gd}_{2} \mathrm{O}_{3}$ doped with $1 \% \mathrm{Bi}$ and $1 \%$ Ho was irradiated in subsequent seven runs for $50 \mathrm{~s}$ each with about 1 min lasting breaks between each run. During all runs 100 spectra were recorded with $0.5 \mathrm{~s}$ integration time of each spectrum. The shapes of all IBIL spectra were similar (Fig. 1). However, the recorded IBIL intensities decreased or increased depending on the ion fluence and sample detention without the ion beam operation (Fig. 2).

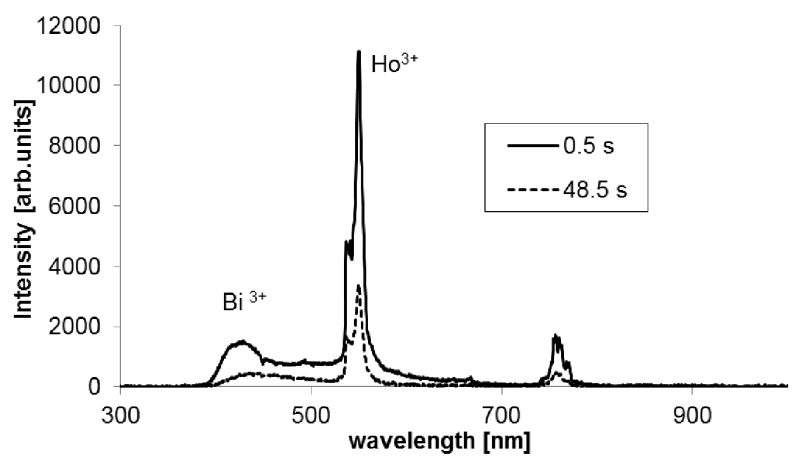

Fig. 1. IBIL spectra of $\mathrm{Gd}_{2} \mathrm{O}_{3}$ powder doped with $1 \% \mathrm{Bi}$ and $1 \% \mathrm{Ho}$ after $0.5 \mathrm{~s}\left(5.7 \times 10^{13} \mathrm{H}^{+} / \mathrm{cm}^{2}\right)$ and after $48.5 \mathrm{~s}\left(5.5 \times 10^{15} \mathrm{H}^{+} / \mathrm{cm}^{2}\right)$ of ion beam irradiation. The sharp intensive lines about $550 \mathrm{~nm}$ are related to the holmium ions, broad violet-blue-green band can be attributed to the bismuth ions.

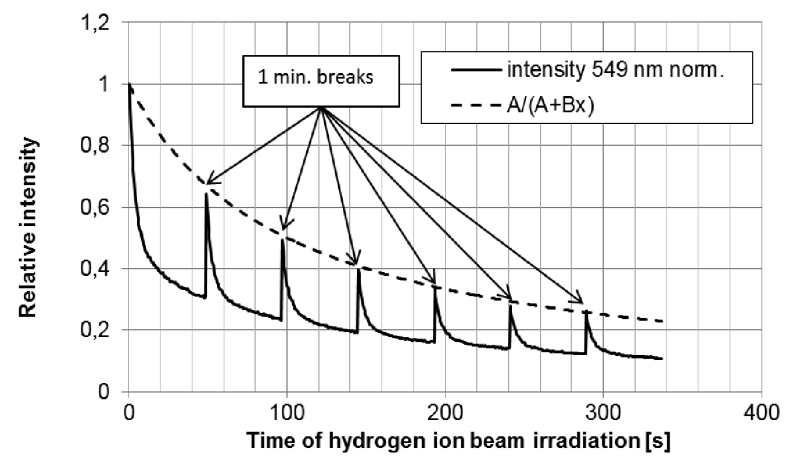

Fig. 2. Related intensities of IBIL spectral line $549 \mathrm{~nm}$ versus time of ion beam irradiation. Arrows indicate moments of ion beam breaks for about 1 min each. Time of breaks is not indicated. Dashed line represents simulation of IBIL intensity degradation by ion induced defects accumulation. $A$ - initial concentration of luminescent centers, $B-$ number of competitive nonluminescent recombination centers generated by one ion, $x$ — ion fluence.

The degradation of IBIL signal with the time of ion beam operation was observed. Two degradation pro- cesses may be distinguished: slower (with the ion implantation time or the ion fluence) persistent degradation and faster degradation partially reversible after the ion beam irradiance ceased. The reversible process may be attributed to heating and cooling of the target material.

The persistent part of the IBIL degradation may be estimated taking into account the IBIL intensity recorded for the cooled target. The degradation curve can be well simulated using the simple model proposed by Gawlik et al. [17]:

$$
I=A /(A+B x)
$$

where $I$ - intensity of the IBIL line, $A$ - concentration of the luminescent centers, $B$ - number of competitive nonradiative recombination centers generated by the incident ion (or per second of irradiation), $x$ - ion fluence (or irradiation time in s). Ion irradiation time and ion fluence can be used alternatively because the ion beam current was kept constant during the whole measurements.

The model of IBIL degradation with ion fluence [17] is based on the assumption that the observed IBIL reduction is caused by competitive nonradiative recombination centers generated by implanted ions.

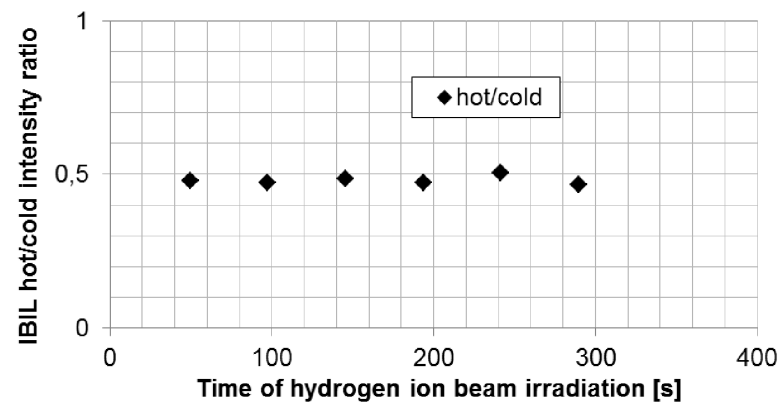

Fig. 3. Proportion between intensities of holmium (Ho) related IBIL line $549 \mathrm{~nm}$ measured just before and just after each cooling step.

Proportion between the holmium IBIL $549 \mathrm{~nm}$ line intensities measured just before and just after each cooling step is constant in the whole measured ion fluence range (Fig. 3). Hence, there are two independent processes observed: the fluence dependent degradation most probably caused by ion induced defects and the second process which is most probably temperature dependent only.

\section{Conclusions}

Concluding, it has been shown that in the gadolinium oxide powders doped with holmium and bismuth heating essentially affects the IBIL signal. In this case target heating by ion beam should be taken into account in designing IBIL measurements. The technique proposed in this paper makes it possible to distinguish ion beam induced IBIL degradation and thermal effects caused by ion beam heating of the target material. Temporary switching of the ion beam and repeating IBIL recording after some cooling time can be used as a fast test 
of thermal effect. Reversible increase of IBIL signal after some break of ion beam irradiation indicates that thermal effects should be separated from the ion beam induced damage of the target material.

\section{References}

[1] M. Khanlary, D.E. Hole, P.D. Townsend, Nucl. Instrum. Methods, Phys. Res. B 227, 379 (2005).

[2] T. Hirouchi, M. Nishiura, T. Nagasaka, T. Ido, D. Funaki, T. Kobuchi, A. Okamoto, S. Kitajima, M. Sasao, K. Fujioka, M. Isobe, T. Mutoch, J. Nucl. Mater. 386-388, 1049 (2009).

[3] F. Sato, T. Tanaka, T. Kagawa, T. Lida, Nucl. Instrum. Methods, Phys. Res. B 210, 281 (2003).

[4] J.R. Huddle, P.G. Grant, A.R. Ludington, R.L. Foster, Nucl. Instrum. Methods, Phys. Res. B 261, 475 (2007).

[5] K.J. McCarthy, J.G. López, D.J. Rey, B. Zurro, A. Ibarra, A. Baciero, M.A. Respaldiza, J. Nucl. Mater. 340, 291 (2005).

[6] P.D. Townsend, M. Khanlary, D.E. Hole, Surf. Coat. Technol. 201, 8160 (2007).

[7] A.A. Bettiol, K.W. Nugent, D.N. Jamieson, Nucl. Instrum. Methods, Phys. Res. B 130, 734 (1997).

[8] H. Calvo, del Castillo, J.L. Ruvalcaba-Sil, M. Barboza-Flores, E. Belmont, T. Calderón, Nucl. Instrum. Methods, Phys. Res. A 580, 400 (2007).
[9] J.L. Ruvalcaba-Sil, L. Manzanilla, E. Melgar, R. Lozano, S. Cruz, X-Ray Spectrometry 37, 96 (2007).

[10] S. Calusi, E. Colombo, L. Guintini, A. Lo Guidice, C. Manfredotti, M. Massi, G. Pratesi, E. Vittone, Nucl. Instrum. Methods, Phys. Res. B 266, 2306 (2008).

[11] A. Quaranta, J.C. Dran, J. Salomon, J.C. Pivin, A. Vomiero, M. Tonezzer, G. Maggioni, S. Carturan, G. Della Mea, J. Phys., Conf. Series 41, 543 (2006).

[12] H. Calvo, del Castillo, J.L. Ruvalcaba, T. Calderón, Anal. Bioanal. Chem. 387, 869 (2007).

[13] C. Manfredotti, E. Vittone, A. Lo Giudice, C. Paolini, F. Fizzotti, G. Dinca, V. Ralchenko S.V. Nistor, Diam. Relat. Mater. 10, 568 (2001).

[14] V.A. Skuratov, K.J. Gun, J. Stano, D.L. Zagorski, Nucl. Instrum. Methods, Phys. Res. B 245, 194 (2006).

[15] G. Gawlik, J. Jagielski, Vacuum 81, 1371 (2007).

[16] G. Gawlik, J. Jagielski, Nucl. Instrum. Methods, Phys. Res. B 266, 1307 (2008).

[17] G. Gawlik, J. Sarnecki, I. Jóźwik, J. Jagielski, M. Pawłowska, Acta Phys. Pol. A 120, 181 (2011). 